DE DE GRUYTER OPEN
Journal of Intercultural Management

Vol. 7, No. 3, September 2015, pp. 133-141

DOI 10.1515/joim-2015-0025

Magdalena Saczyna 25

\title{
Achieving Environmental Sustainability through Knowledge Management: a Survey Conducted among Corporates in the Czech Republic
}

\begin{abstract}
It is now widely recognized that knowledge assets and technological enhancements are essential strategic resources for any organisation to achieve competitive advantage and sustainability. The imperative for achieving this efficiency is in transfer of relevant information for decision-making across all levels of company structure. It can be done with well-disposed knowledge management system, that improves the overall corporate performance. This paper examines how companies in Czech Republic manage their internal knowledge associated with environmental sustainability so as to improve their overall corporate performance.
\end{abstract}

Key words: Environmental sustainability, Sustainability, Knowledge Management.

\section{Introduction}

The globalization brought the enormous changes in business thinking and technologies that have impact on organizations worldwide. The organizations who want to survive in unpredictable and complex competitive markets should quickly adapt to the new dynamics of business. In the last decades sustainability, defined as development which meets the needs of the present without compromising the ability of future generations to meet their own needs [Brundtland Commission 1987], has become an increasingly integral part of doing business in any industry. As at today, there is no clear definition on what sustainability means to corporate. Henceforth, corporates are left with their own interpretation and imagination as to the application of concept of sustainable development to their businesses. However, to improve organisational sustainability-related performance, executives

${ }^{25}$ saczyna.m@gmail.com 
have to recognise and better understand the key sustainability-related knowledge assets available within and across organisations. The imperative for achieving this efficiency is in transfer of relevant information for decision-making across all levels of company structure. It can be done with well-disposed knowledge management system, that improves the overall corporate performance. However, a recent survey found that $85 \%$ of organizations find their ability for strategical knowledge management weak, while $70 \%$ of these same organizations believe knowledge assets can fuel growth in both revenues and core competencies [Arthur 1987].

The aim of this paper is to present results of researches on how companies in Czech Republic manage internal knowledge associated with environmental sustainability so as to improve their overall environmental performance.

The research process is identified into two key phases that are the literature review and the main study. The review of literature involved background study on knowledge management and corporate environmental sustainability management. This resulted in the development of a theoretical framework. Interviews were carried out between Mai and November 2014 among 18 sustainability coordinators and 127 random employees in Czech subsidiaries of international corporates. All surveyed were asked questions concerning creation, documentation, dissemination and utilization of environmental knowledge from the perspective of company sustainability strategy.

\section{Environmental Knowledge Management}

Environmental sustainability refers to meeting the resources and services needs of current and future generations without compromising the health of the ecosystems that provide them [Morelli 2011, pp. 19-27]. Effective management of environment related knowledge provides employees with instructions concerning desired behavior and increases capacity to take effective actions in respect of environmental sustainability, thus employees fulfill their mission in the company, which reaches the corporate objectives and strategies.

Davenport and Prusak view knowledge as an evolving mix of framed experience, values, contextual information, and expert insight that provides a framework for evaluating and incorporating new experiences and information that becomes embedded in documents or repositories and in organizational routines, processes, practices, and norms [Davenport, Prusak 1998, p.5].

Knowledge management is a discipline that promotes an integrated approach to identifying, capturing, evaluating, retrieving, and sharing all of an enterprise's information assets. These assets may include databases, documents, policies, procedures, and previously un-captured expertise and experience in individual workers [Duhon 1998, pp. 8-13]. Its goal is to provide the right information to the right person at the right time. Henceforth, knowledge management in environmental 
aspect represents goals, measures, structures, and processes to provide roadmaps for how to document, communicate, generate and utilize knowledge [ReinmannRothmeier, Mandl, Erlach 2001].

\section{Knowledge Creation}

In the literature five modes of knowledge generation are discussed: acquisition, dedicating resources, fusion, adaptation, and building knowledge networks [Choo 2003, pp. 205-220]. Through selection of new employees on the basis of their commitment to sustainability an organization builds a pool of human capital with values and skills that support the organization journey toward sustainability. An organization transitioning toward sustainability should also consider referring to its sustainability values, goals and performance in recruiting materials to attract candidates that will align with these values. Organizations may also dedicate resources to the generation of knowledge by establishing units that undertake research and development. Knowledge generation through fusion can occur when different individuals and groups with different specializations and perspectives are brought together to work on a problem or project. Adaptation takes place when the organization responds to new conditions in its external environment.

The purpose of the knowledge assimilation is using the knowledge in the way to reduce gap between the knowledge that is needed and the knowledge that is currently available. This can happen through the conversion of tacit knowledge into explicit knowledge and back again.

Tacit knowledge is the type of knowledge acquired predominantly through experience. It is personal, hard to formalize and communicate to others [Hansen, Nohria, Tierney 1999, pp. 106-116]. This suggests that tacit knowledge may be best transferred through more interpersonal means and using processes that are less structured like mentoring, teamwork, chat rooms, personal intranets, and opportunities for face-to-face conversations such as group dialogue or personal reflections on experiences and lessons learned. Explicit knowledge is what is written or recorded in manuals, patents, reports, documents, assessments, and can be readily codified, articulated, and captured [Nonaka, Ikujiro, Takeuchi 1995, p. 8]. It can be transferred through more technology-driven, structured processes such as information systems or a mailbox.

To improve organisational sustainability-related performance, executives have to recognise and better understand the key sustainability-related knowledge assets available within and across organisations. It is critical for organisations to understand the key drivers before implementing sustainability-related knowledge management initiatives. The most recognized four enterprise settings for organizational knowledge management are culture, leadership, technology, and measurement [Arthur Andersen Business Consulting 1999]: 
- Culture. A corporate culture of environmental sustainability is one in which organizational members hold shared assumptions and beliefs about the importance of environmental accountability. The organization culture should be constructed to encourage organizational learning, and knowledge creation, so as to promote the improvement of organizational learning ability and the exchange and sharing of knowledge. Organisations should create spaces (personal conversations, environmental teams) and places (talk rooms, knowledge fairs, open forums, environmental corners) where knowledge transfer can happen. Most of the impediments are related to the culture of the organization. Enterprise should encourage and drive employees to share and exchange their knowledge, so as to expand the space of knowledge creation, and thus bring potential benefit. This may have form of knowledge transfer platforms as well as provision of necessary resources to support engagement, e.g., education and training budget, time, information, backfilling. Moreover enterprise should set up an assessment and feedback system, an incentive mechanism that rewards employees that actively take part in the process of knowledge transfer, sharing and creation. Thus it can be ensured that there is enough enthusiasm and momentum for active exploitation of knowledge source inside the organization.

- Leadership. Many studies confirm strong connection between board members commitment for corporate sustainability and its program's successful implementation [Adriana 2009, p.1385-1392]. Leadership strategies in industries include strategic planning of knowledge management in alignment with mission/ vision, hiring knowledgeable employees, clarifying roles and competencies required for managing sustainability initiatives, identification of employees with sustainability related skills to place them where their skills are needed, as well as evaluating employees for knowledgeable contribution. Leadership is essential to stimulate staff motivation to access the various sources of knowledge and to encourage employees to share their tacit knowledge [Kuo, Chu 2004, p. 331]. Leadership supporting sustainability requires a rewards and recognition program to support and reinforce sustainability behaviors as well as establishment of management structure to execute proenvironmental strategy strategy.

- Technology. Company is responsible for providing infrastructure of tools, systems, platforms and automated solutions among others in form of email, groupware, data translation services and intranet that foster the development, application, and distribution of organizational knowledge. Infrastructure systems connect the members of the organisation and allow them to communicate on all levels [Moore 2010].

- Measurement. Measurement strategies may include benchmarking against other industries, allocating resources toward efforts that measurably increase the knowledge base, and linking and accessing impact of KM to the strategic plan. 


\section{Knowledge Documentation}

Knowledge documentation includes all methods and processes that can be implemented to make environmental knowledge more transparent to employees. To incorporate sustainability into corporate strategy many companies choose to make investments in some form of environmental management systems or sustainability management systems that may have form of an in-house solution or recognized external system such (EMAS, GRI, AA 1000 or ISO 14001). Many companies also decide to introduce product / process specific certifications such as Fairtrade, LEED green building system or the Forest Stewardship Council. These solutions call for documentation in form of manuals, procedures, instructions, records or written strategies. Some of above mentioned strategies recommend introduction of written commitments procedures, where employees acknowledge and commit to comply with environmental strategy principles. Employees should be also provided with explicit clues on the location of stored documentation. The presentation of knowledge, both internal and external, forms the basis for its communication.

\section{Knowledge Communication}

Knowledge communication includes all processes and methods for sharing and disseminating knowledge including the use of technical support tools such as the Intranet or E-mail. On an individual level, it is important to consider the competence, motivation and volition of the knowledge communication. Powerful tool for communication of both tacit and explicit knowledge is creation of platform in form of working groups, regular meetings or network of environmental ambassadors. Knowledge communication not only facilitates the circulation of information, but also leads to the generation of new knowledge.

\section{Knowledge Utilization}

The literature recognises four major dimensions of knowledge utilization that are: source, content, medium and users [National Center for the Dissemination of Disability Research (NCDDR) 1996]:

- Source is defined as entity responsible for creating the new knowledge or for conducting dissemination activities. One of the most important findings from the research on dissemination is that the source of information disseminated generally is more important to users than the content of the information [Hutchinson, Huberman 1993, p.15]. Moreover users tend to accept assistance, information, and ideas from sources they know and trust [Carrillo, Lumbley, Westbrook 1984].

- Content attributes that may have influence on adoption of the knowledge are: the quality of the content, the compatibility of users' needs and beliefs, specific kinds of information that promote utilization of research results, and the 
comprehensibility of results. Moreover it is recommended that materials should emphasize positive behavior and current rewards more than negative and distant consequences of current behavior[Backer 1988, pp. 18-22].

- A dissemination medium can be defined as ways in which the knowledge is described and transmitted. The selection of the dissemination media most appropriate for a particular content and audience is a complex and challenging task. The literature indicates direct personal interaction to be the most important aspect of an effective medium for disseminating information [Paisley 1993, pp. 222-234].

- Users. The materials to be disseminated should address the concerns of a potential user's daily life and thus be brought down to the individual level by connecting the impact of everyday actions at work with environmental sustainability at home. This can be done by involving potential users in all knowledge management processes from the beginning, with ongoing and substantial interactions between knowledge source and users that can be tightened through encouragement of mutual dialogue or feedback. Another implication involves the user's readiness for change. Even the clearest results will not be utilized if the potential user is not ready to incorporate them into their personal existing schemata. Thus many studies highlight the importance of developing baselines before charging ahead with sustainability. The assesment of employees' readiness for change is a backbone for creation of change mechanisms that are appropriate for the employees' state [Doppelt 2008].

\section{Results}

On the basis of the conducted interviews following results were obtained:

\section{Knowledge creation}

According to interviewed coordinators the main source of the information on environmental issues were sustainability department in headquarter or local body responsible for environmental management system. $28 \%$ of coordinators confirmed that environmental values of candidates is of importance in the staff recruitment process.

\section{Knowledge documentation}

The interviewed coordinators mostly indicated documentation in form of strategy, codes of conduct, reports as well as documentation being integral part of already existing solutions in environmental aspect including environmental management systems or facility management. These were howerever not an obligatory source of information for employees. According to the survey results, documentation seemed to be more targeted at external stakeholders including 
media, potential partners or customers. WIth this strategy organisations aim to improve their competetiveness on the market, more than to stimulate employees to behaviour change. Moreover, only in $7 \%$ of organisations employees were in the two last years examined on their opinion and attitude to corporate sustaniable interventions (this happened mostly through anonymous feedback questionaire). Interviewed coordinators admitted that documentation of current internal events (short-term projects, workshops) with environmental focus is stored, mostly for coordinator and management use, on the local server.

\section{Knowledge communication}

Survey also revealed weak internal communication strategy of examined organisations. Only 32 of 127 employees were able to correctly alledge the body in corporate that is responsible for environmental sustainability strategy. $37 \%$ of employees admitted being informed about upcoming workshop on environmental issues, however due to lack of interest or ineffective message form, most of the them ignored the announcement. In examined organisations internal communication happened mainly through dissemintation of posters and intranet. Interviews revealed no explicit internal social platform/community or a contact person in respect to environmental issues in organisation.

\section{Knowlegde utilisation}

- Source. Only 32 of 127 employees were able to give a correct answer when asked for the name of organisation entity /person responsible for environmental issues in the corporate. Over $80 \%$ of persons questioned indiced that HR department is responsible for organisation of environmental activities for employees and dissementation of aspects related to environmental knowledge. Also interviewed coordinators were not able to define an explicit and direct entity in corporate that would be responsible for all management processes framing internal environmental knowledge including its generation, communication, documentation and implementation among employees.

- Contents. The conducted study confirms that companies put more emphasis on external communication of environmental strategy. The internal communication is limited to information referring to new regulations, overall results of environmental performance or event announcements. The results of interviews showed that these contents only to limited extend provide employees with instructions that would foster their proevironmental behaviour in the workplace.

- Medium. Over 70\% of coordinators pointed intranet and posters as the most common dissemination canals for environmental knowledge transfer. Neither coordinators nor employees were able to identify any stable or long-term social platfom like working teams or meetings groups in their organisations. 
- Users. Interviewed coordinators judged corporate employees interest and involvement in environmental activities as very poor. The environmental strategies claimed to be urged by the top management without intensive involvement of employees.

\section{Conclusions}

1. The growing Czech market of corporate sustainablity reports and commitments allows concluding that Czech companies are on the transformation path to embed environmental sustainability into corporate culture [Trnková 2004]. However results presented in this paper show that knowlege management strategies connected to this context still seem to be more adressed to external stakeholders and little focus is given to internal resources. In the Czech Republic the imperative role of employees as source of knowledge still seem to be underestimated. Results of conducted research show that there are still many dimenions of knowledge management that need to be improved. These are among othersCreation of social platforms for knowledge generation and exchange.

2. Clear leadership through assignment of (supporting) team in charge of all processes of internal environmental knowledge management.

3. Involvement of employees in knowledge management processes as well as fostering the dialogue with the responsible body (feedback, suggestion, assesment).

4. Transparency of documentation.

The fact is that learning and growth perspective essentially means the quality of human resources in company. Thus investing in employees should not be considered to be more cost but an investment. To keep up with the time it is essential that employees continually improve and learn, and develop corporate proenvironmental culture and attitudes with respect to individual and corporate advance.

\section{References}

Adriana B. (2009), Environmental supply chain management in tourism: The case of large tour operators, „Journal of Cleaner Production”, 17(16).

Arthur A. (1996), The Knowledge Management Tool: External, The American Productivity and Quality Center (APQC).

Arthur Andersen Business Consulting (1999), Zukai Knowledge Management, Keizai Inc., Tokyo.

Backer T.E. (1988), Research utilization and managing innovation in rehabilitation organizations, "Journal of Rehabilitation“, 54(2).

Brundtland Commission (1987), Report of the World Commission on Environment and Development, United Nations.

Carrillo R., Lumbley J., Westbrook J. (1984), Effective networking: The role of the consultant, „Consultant", 3(2). 
Choo C.W. (2003), Perspectives on Managing Knowledge in Organizations. Knowledge Organization and Classification in International Information Retrieval, Binghampton, New York.

Davenport T.H., Prusak L. (1998), Working knowledge: how organisations manage what they know, Harvard Business School Press, Boston.

Doppelt B. (2008), The power of sustainable thinking, Earthscan Publications Ltd, London.

Duhon B. (1998), It's All in our Heads, "Inform", 12 (8).

Hansen M., Nohria N., Tierney T. (1999), What's your strategy for managing knowledge? „Harvard Business Review“, 77(2)

Hutchinson J., Huberman M. (1993), Knowledge dissemination and utilization in science and mathematics education: A literature review, National Science Foundation, Washington.

Kuo Y., Chu T. (2004), An Investigation of Effort-accuracy Trade-off and The Impact of Self-efficacy on Web Searching Behavior, Decision Support System.

Moore S.A. (2010), The effect of knowledge sharing on the environmental performance of proactive environmental organisations, Southern Cross University

Morelli J. (2011), Environment Sustainability: A Definition for Environment Sustainability, „Journal of Environment Sustainability", 1.

National Center for the Dissemination of Disability Research (NCDDR) (1996), A Review of the Literature on Dissemination and Knowledge Utilization.

Nonaka I., Hirotaka T. (1995), The Knowledge-Creating Company: How Japanese Companies Create the Dynamics of Innovation, Oxford University Press, New York.

Paisley W. (1993), Knowledge utilization: The role of new communications technologies, „Journal of the American Society for Information Science“, 44(4).

Reinmann-Rothmeier G., Mandl H., Erlach C., Neubauer A. (2001), Wissensmanagement lernen. Ein Leitfaden zur Gestaltung von Workshops und zum Selbstlernen, Beltz, Weinheim.

Trnková J. (2004), Společenská odpovédnost firem - kompletníprưvodce tématem \& závéry z.prĩžkumu $v$ CR, Business Leaders Forum v rámci European Business Campaign for CSR, Prague. 